\title{
Mixed micellar system stabilized with saponins for oral delivery of vitamin K
}

\author{
Feilong Sun $^{\mathrm{a}}$, Chengpei Ye ${ }^{\mathrm{a}}$, Kaushik Thanki ${ }^{\mathrm{b}}$, Donglei Leng ${ }^{\mathrm{b}}$, Peter M. van Hasselt ${ }^{\mathrm{c}}$, \\ Wim E. Hennink ${ }^{\mathrm{a}}$, Cornelus F. van Nostrum ${ }^{\mathrm{a}, *}$ \\ a Department of Pharmaceutics, Utrecht Institute for Pharmaceutical Sciences, Utrecht University, 3584 CG Utrecht, The Netherlands \\ ${ }^{\mathrm{b}}$ Department of Pharmacy, Faculty of Health and Medical Sciences, University of Copenhagen, Universitetsparken 2, DK-2100 Copenhagen $\emptyset$, Denmark \\ ${ }^{\mathrm{c}}$ Department of Pediatrics, Wilhelmina Children's Hospital, University Medical Center Utrecht, Lundlaan 6, 3584 EA Utrecht, The Netherlands
}

\section{A R T I C L E I N F O}

\section{Keywords:}

Vitamin K

Micelles

Saponins

Bile

Oral delivery

Cholestasis

\begin{abstract}
A B S T R A C T
Poorly soluble vitamin K cannot be absorbed by patients suffering from cholestasis due to extremely low level of bile salts in the intestine. A formulation of vitamin $\mathrm{K}$ including glycocholic acid (i.e. Konakion ${ }^{\circledR} \mathrm{MM}$ ), does not increase bioavailability because it is unstable due to protonation of glycocholic acid at gastric pH. To develop a stable formulation, saponins were introduced as neutral surfactants to (partly) replace glycocholic acid. Experimental design was made to investigate the effect of the composition on particle size at neutral $\mathrm{pH}$ and upon acidification at $\mathrm{pH}$ 1.5. Two formulations that were within the optimized composition window were loaded with vitamin $\mathrm{K}$ and those showed superior stability at low $\mathrm{pH}$ as compared to Konakion ${ }^{\circledR} \mathrm{MM}$ : sizes were between 43 and $46 \mathrm{~nm}$ at $\mathrm{pH} 7.3$ and between 46 and $58 \mathrm{~nm}$ after $1 \mathrm{~h}$ incubation at $\mathrm{pH} 1.5$, respectively, but large aggregates were formed at $\mathrm{pH} 1.5$ in presence of Konakion ${ }^{\circledR}$ MM. Micelles were cytocompatible with Caco-2 cells at concentration of surfactants (saponins and glycocholic acid) up to $0.15 \mathrm{mg} / \mathrm{ml}$. Uptake of vitamin $\mathrm{K}$ by Caco-2 cells was $4.2-4.9 \mathrm{nmol} / \mathrm{mg}$ protein for saponins-containing formulations and $7.1 \mathrm{nmol} / \mathrm{mg}$ protein for Konakion ${ }^{\circledR}$ MM. This, together with the superior stability at low $\mathrm{pH}$, makes saponins-containing mixed micelles promising oral formulations for vitamin $\mathrm{K}$.
\end{abstract}

\section{Introduction}

Vitamin K serves as an essential cofactor for $\gamma$-glutamyl carboxylase, an enzyme that catalyzes the carboxylation of glutamic acid residues in a number of proteins that are involved in the blood coagulation [1], and plays a key role in haemostasis. The inactivity of the vitamin K-dependent clotting factors VII, IX, X, and prothrombin in case of profound vitamin $\mathrm{K}$ deficiency causes spontaneous bleedings, which may be life threatening, particularly in infants with cholestasis due to extremely low level of bile salts and hence poor absorption of vitamin $\mathrm{K}$ in the intestine.

Konakion $^{\circledR}$ mixed micelles (MM) is a clinically used formulation composed of vitamin K, egg phosphatidylcholine (EPC or lecithin) and glycocholic acid [2]. It is used for both the prophylaxis and treatment of vitamin $\mathrm{K}$ deficiency bleeding (VKDB) in neonates and infants. As reported in earlier studies, prophylactically administering Konakion ${ }^{\circ} \mathrm{MM}$ orally fails to prevent VKDB in cholestatic infants [3], which is thought to be due to the pathophysiological conditions in the upper gastrointestinal tract of those infants. It was found that Konakion ${ }^{\star} \mathrm{MM}$ are unstable and form large aggregates at the low $\mathrm{pH}$ of the stomach because of protonation of the carboxylate group of glycocholic acid, eventually causing coalescence of the formulation $[4,5]$. Once vitamin $\mathrm{K}$ is phase separated in the stomach, its absorption is dependent on the presence of sufficient amount of endogenous bile in the intestine. After passage through stomach in healthy infants, the coalesced vitamin $\mathrm{K}$ can be solubilized by endogenous bile in the intestine [6-8]. However, in cholestatic patients, the levels of endogenous bile salts are very low, which in turn results in extremely low absorption of vitamin $\mathrm{K}$ from Konakion ${ }^{\circledR}$ MM [9]. Thus, avoiding coalescence and subsequent phase separation of the formulation at gastric low $\mathrm{pH}$ is important for sufficient absorption of vitamin $\mathrm{K}$.

To improve the colloidal stability of micellar formulation of vitamin $\mathrm{K}$ at gastric low $\mathrm{pH}$, one strategy is to introduce poly(ethylene glycol) [10] as a steric barrier, however these PEGylated mixed micelles displayed a pronounced reduction in both cellular uptake and transport through Caco-2 cell monolayers. PEG is a synthetic polymer and previous studies have demonstrated that PEGylation can indeed reduce the cellular uptake of nanoparticles [11-13]. Another strategy to improve micelles'colloidal stability is to partially replace glycocholic acid in Konakion MM by a non-ionic surfactant. Saponins, which are of natural sources are chosen as they are biocompatible, safe and cost-effective for scale-up production. Saponins are constituents of a wide variety

\footnotetext{
* Corresponding author.

E-mail address: C.F.vanNostrum@uu.nl (C.F. van Nostrum).
} 


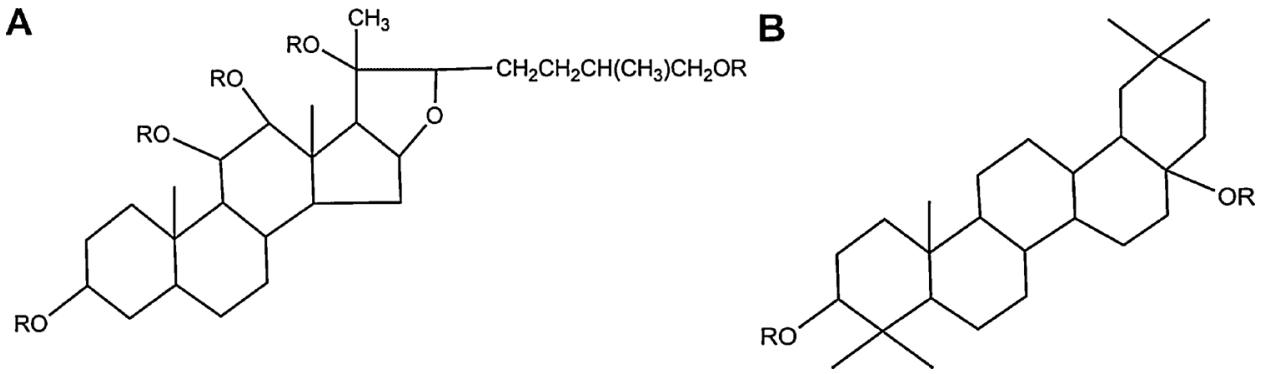

Fig. 1. Chemical structures of (A) steroidal and (B) triterpenoid saponins, $R=$ glucose, galactose, rhamnose, xylose, hexose, etc. [28,29].

of plants (such as quillaja bark and soybean) and consist of polycyclic aglycone as the hydrophobic tail, which is attached to one or several saccharide chains through a glycoside bond. The aglycone part is either a steroid or a triterpene, and the sugar chain can vary in both numbers and length [14-16] (Fig. 1). Saponins can self-assemble into micelles in aqueous solution, in which the non-ionic hydrophilic sugar chains point towards the aqueous phase and the hydrophobic aglycones form the inner core [17-19]. Because saponins used in this study have noncharged sugar moieties (product information from Sigma-Aldrich) [20], and therefore they are $\mathrm{pH}$ inert and form micelles with stability independent of the $\mathrm{pH}$ [21]. Recently, saponins gained clinical interest because of their membrane permeabilizing properties toward intestinal epithelial cells and these compounds have shown to be able to increase the oral bioavailability of therapeutic drugs [22-25].

The aim of this work was to develop a gastric-stable mixed micellar formulation for oral delivery of vitamin $\mathrm{K}$ in which glycocholic acid is partially substituted by saponins aiming to prevent acid induced micellar coalescence. An experimental design approach revealed two mixed micelle formulations that were the most stable at gastric $\mathrm{pH}$ and they were selected to load vitamin K. Caco-2 cells were used to investigate the cytocompatibility and cellular uptake of above two mixed micelle formulations of vitamin $\mathrm{K}$ containing saponins and glycocholic acid. Cellular uptake by Caco-2 cells is well predictive for epithelial transport $[26,27]$.

\section{Materials and methods}

\subsection{Materials}

Lecithin (egg phosphatidylcholine, EPC) was bought from Lipoid $\mathrm{GmbH}$ (Ludwigshafen, Germany). Chloroform was purchased from Biosolve (Valkenswaard, the Netherlands). Ethanol was supplied by Merck KGaA (Darmstadt, Germany). Konakion ${ }^{\circledR}$ MM ampoules were purchased from Roche (Basel, Switzerland). Saponins (8-25\% sapogenin, product number 84510 ), sodium glycocholate hydrate, vitamin $\mathrm{K}$, fetal bovine serum (FBS) and all other chemicals and reagents were purchased from Sigma-Aldrich (Zwijndrecht, The Netherlands). Dulbecco's Modified Eagle's Medium (DMEM) was provided by GibCo BRL Life Technologies (Carlsbad, CA, USA). CellTiter $96^{\circledR}$ Aqueous One Solution Cell Proliferation Assay kit was obtained from Promega (Leiden, the Netherlands). Hoechst dye 33342 was bought from Molecular Probes (Eugene, OR, USA). Syringe filters $(0.2 \mu \mathrm{m})$ were acquired from Phenomenex (Torrance, CA). Ultrapure water was produced by a Synergy UV water delivery system from Millipore (Billerica, MA, USA).

\subsection{Construction of ternary phase diagrams}

An extreme vertices design [30] was chosen in order to analyze the effects of mixture components on sizes of mixed micelles at both neutral and acidic $\mathrm{pH}$ (7.3 and 1.5, respectively). Ternary diagrams of saponins (S), glycocholic acid (G) and EPC were plotted, each of which represents an apex of the triangle. The weight fractions of S, G and EPC were varied from 0.00 to $0.50(\mathrm{w} / \mathrm{w}), 0.00$ to $0.50(\mathrm{w} / \mathrm{w})$ and 0.45 to $0.90(\mathrm{w} / \mathrm{w})$, respectively (see Section 2.3 for method of preparation of mixed micelle formulations). For all mixtures, the total of S, G and EPC weight fractions always added to 1 . Twenty-seven mixtures with varying compositions were prepared (Supplementary material Table S1). The response variables were set as sizes of micelles after preparation at $\mathrm{pH} 7.3$ and after $1 \mathrm{~h}$ incubation at $\mathrm{pH} 1.5$, in water at $37^{\circ} \mathrm{C}$, and the corresponding ratio of size ${ }_{(\mathrm{pH} 1.5)} / \mathrm{size}_{(\mathrm{pH}}$ 7.3). A twenty-seven run design was executed, response variables for each run were recorded (Supplementary material Table S1, all formulations were prepared in triplicate and responses were presented as mean $\pm S D, n=3$ ). Ternary diagrams were employed for graphical representations of the obtained response variables using Design-Expert software (Trial Version 10.0, Stat-Ease Inc., MN). The responses were separately fitted into various polynomial models and the statistically valid model was chosen as a best-fit model [30]. The obtained responses were model fitted using analysis of variance in a manner to have (i) statistically significant model at $95 \%$ confidence interval (ii) acceptable R-squared values ( $>0.7$ ), (iii) difference between adjusted R-squared and predicted Rsquared is less than 0.2 , and (iv) adequate precision value is more than $4[31,32]$.

\subsection{Preparation of mixed micelle formulations}

For the preparation of empty micelles, glycocholate (from 0 to $42 \mathrm{mg}$ ) and EPC (from 19-58 mg) were dissolved in $8 \mathrm{ml}$ of chloroform/ ethanol $(1 / 1, \mathrm{v} / \mathrm{v})$ in a $100 \mathrm{ml}$ round-bottom flask and the solvents were evaporated under vacuum at $60^{\circ} \mathrm{C}$ for $20 \mathrm{~min}$ to form a film [33-35]. Next, saponins (from 0 to $42 \mathrm{mg}$ ) were dispersed in $5 \mathrm{ml}$ water and this mixture was used to hydrate the film. Next, the dispersions were magnetically stirred for at least $1 \mathrm{~h}$ at room temperature, subsequently transferred into a $15 \mathrm{ml}$ Falcon tube (Becton Dickinson) and sonicated for $90 \mathrm{~s}$ with $30 \mathrm{~s}$ intervals for 6 cycles using a probe sonicator $(18 \%$ intensity, Cole-Parmer 4710 Ultrasonic Homogenizer, Instrument Co., Chicago, IL). Next, the tubes were immersed in ice cold water to cool down the dispersions during the sonication. Finally, the resulting dispersions were extruded 2 times through a syringe filter (pore size is $0.2 \mu \mathrm{m}$ ). The $\mathrm{pH}$ of the above dispersions was adjusted to 7.3 by $1 \mathrm{M}$ $\mathrm{NaOH}$.

Selected stable formulations of mixed micelles (F8 and F9 in Supplementary material Table S1) were loaded with vitamin K. To investigate the vitamin $\mathrm{K}$ loading capacity, 38, 50 or $100 \mu$ of vitamin $\mathrm{K}$ stock solution $(100 \mathrm{mg} / \mathrm{ml}$ in chloroform) were added and mixed with EPC (feeding ratio of vitamin $\mathrm{K}$ against total lipid was 10.0, 13.2 and $26.3 \%(\mathrm{w} / \mathrm{w})$, respectively) and glycocholic acid (7.8 or $9.4 \mathrm{mg}$ ) to form a film. For the preparation of vitamin $\mathrm{K}$ loaded fluorescently labeled mixed micelles, $1.3 \mathrm{ml}$ of 1,2-Dioleoyl-sn-glycero-3-phosphoethanolamine-N-(lissamine rhodamine B sulfonyl) (rhodamine conjugated PE, Avanti Polar Lipid, Inc) solution in chloroform $(117 \mu \mathrm{M})$ was added to the mixture. The rest of the procedure was the same as described above for preparation of empty micelles. 
Table 1

ANOVA analysis of responses of $\left.\operatorname{size}_{(\mathrm{pH}} 1.5\right), \operatorname{size}_{(\mathrm{pH}}$ 7.3) and ratio of $\operatorname{size}_{(\mathrm{pH} 1.5)} /$ $\operatorname{size}_{(\mathrm{pH}}$ 7.3) of mixed micellar compositions containing saponins, glycocholic acid and EPC.

\begin{tabular}{llll}
\hline $\begin{array}{l}\text { Statistical } \\
\text { parameters }\end{array}$ & Responses & & \\
\cline { 2 - 4 } & Size at $\mathrm{pH} 7.3$ & Size at $\mathrm{pH} 1.5$ & $\begin{array}{l}\text { Ratio }(\text { size }(\mathrm{pH} 1.5) / \text { size } \\
(\mathrm{pH} 7.3)\end{array}$ \\
\hline Model $p$-value & $<0.0001$ & $<0.0001$ & $<0.0001$ \\
$\mathrm{R}_{\text {squared }}$ & 0.96 & 0.77 & 0.91 \\
Adjusted $\mathrm{R}_{\text {squared }}$ & 0.95 & 0.72 & 0.87 \\
$\begin{array}{l}\text { Predicted } \mathrm{R}_{\text {squared }} \\
\text { Adequate precision }\end{array}$ & 0.93 & 0.61 & 0.75 \\
& 31.00 & 11.65 & 15.61 \\
\hline
\end{tabular}

\subsection{Characterization of mixed micelle formulations}

Average size and size distribution of empty micelles at $\mathrm{pH} 7.3$ were determined by Dynamic Light Scattering (DLS, Malvern Instruments,

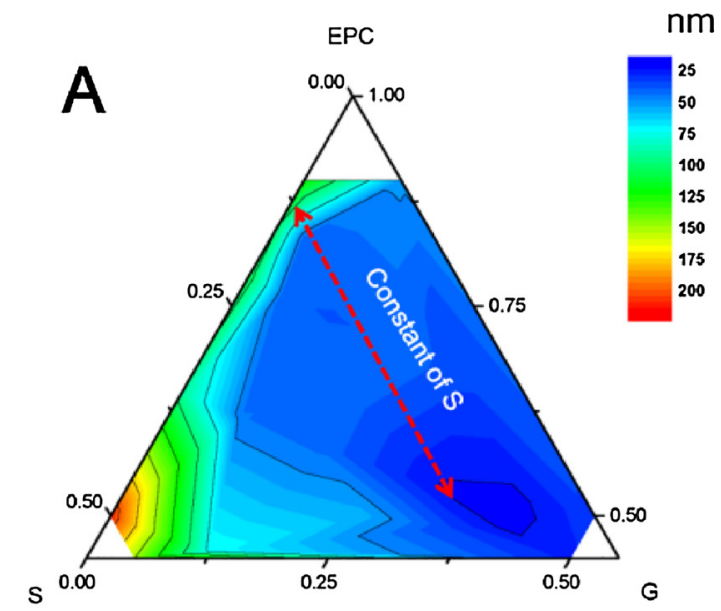

Malvern, UK) at $25^{\circ} \mathrm{C}$ and at angle of $90^{\circ}$. The $\mathrm{pH}$ of the dispersions $(1 \mathrm{ml})$ was lowered to $\mathrm{pH} 1.5$ with $1 \mathrm{M} \mathrm{HCl}$ and the dispersions were subsequently incubated for $1 \mathrm{~h}$ at $37^{\circ} \mathrm{C}$. Then particle sizes were determined again by DLS measurements.

Average size and size distribution of vitamin K loaded micelles were determined using DLS. The lipid recovery was determined by measuring the amount of rhodamine conjugated DSPE as described in Section 2.6. Vitamin $\mathrm{K}$ loaded micelles $(1.0 \mathrm{ml})$ were diluted with $30 \mathrm{mM}$ HEPES buffer $(0.5 \mathrm{ml}, \mathrm{pH} 7.3)$ and their zeta potentials were determined by Zetasizer (Malvern Instruments Ltd.). The instrument was calibrated by a standard (DTS1235, $-42.0 \pm 4.2 \mathrm{mV}$, Malvern Instruments, UK). The morphology of vitamin $\mathrm{K}$ loaded F8K was visualized using Transmission Electron Microscopy (TEM, Tecnai 10, Philips, and $100 \mathrm{kV}$ ). The samples for TEM visualization were prepared as follows. A sample of the mixed micelles dispersion $(10 \mu \mathrm{l})$ was pipetted onto parafilm and a carbon-coated copper grid was placed on the sample for $4 \mathrm{~min}$. Next, the excess liquid was removed by a filter paper and the grid was negatively stained by pipetting a $10 \mu \mathrm{l}$ droplet of $2 \%$ uranyl acetate in demineralized water for $1 \mathrm{~min}$. Next, the excess liquid was removed
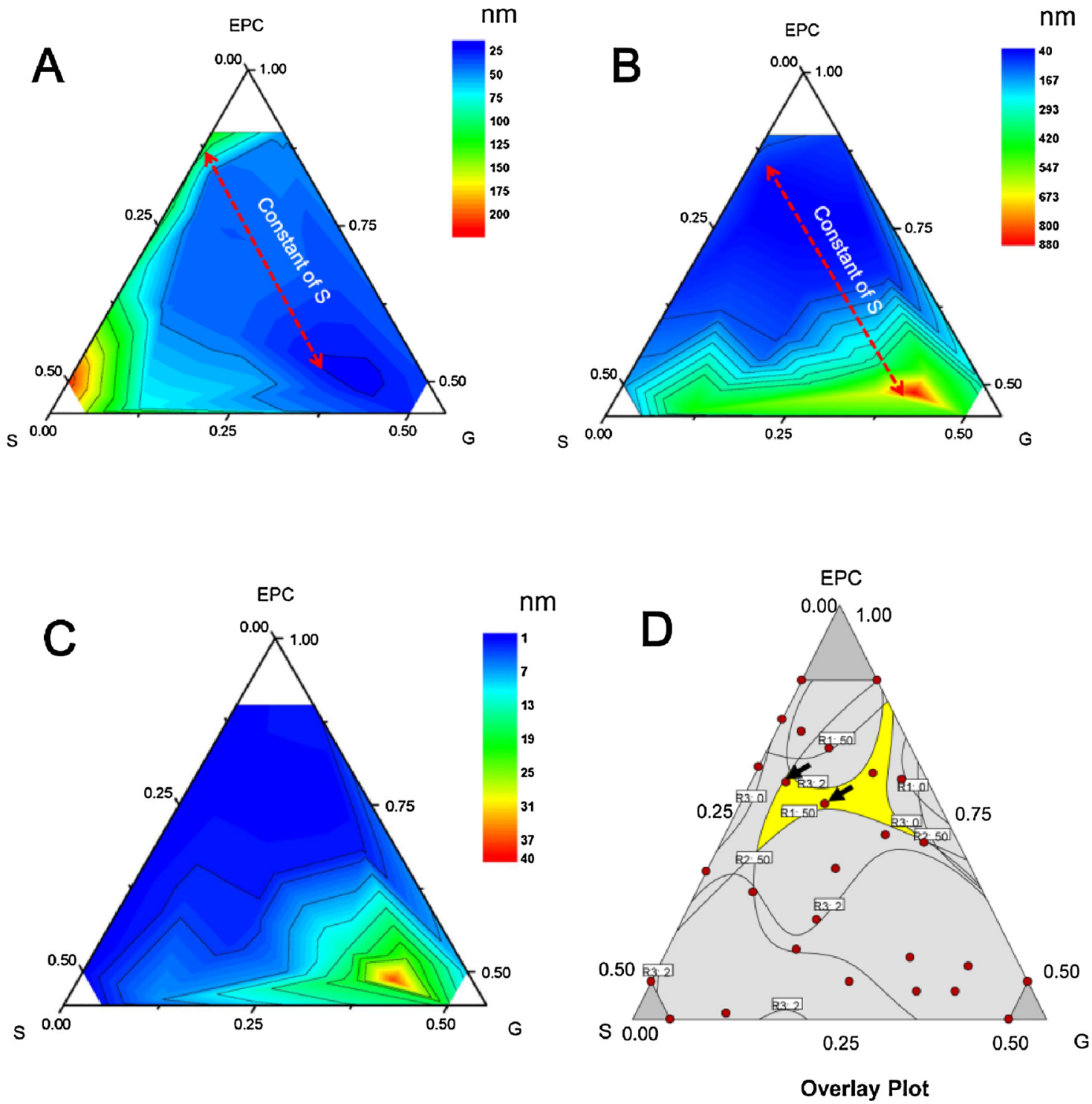

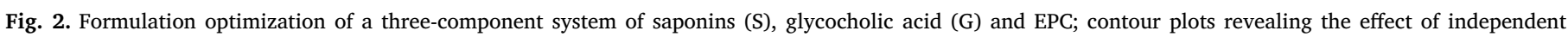

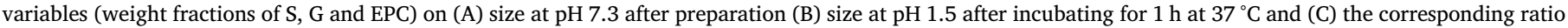

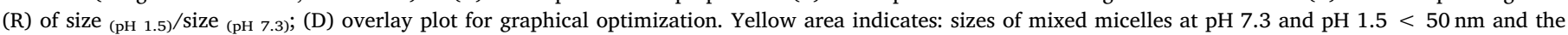

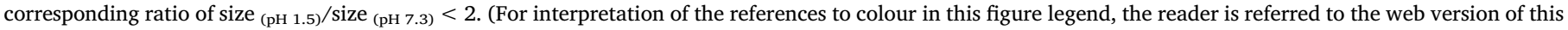
article). 


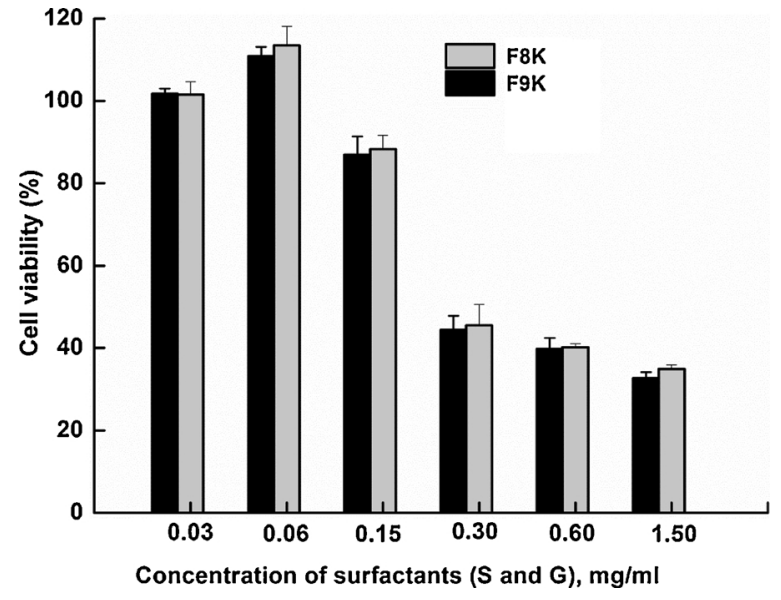

Fig. 3. In vitro cell viability of Caco- 2 cells incubated for $36 \mathrm{~h}$ with F8K and F9K, one representative experiment in triplicate for each sample, results represent mean $\pm \mathrm{SD}$.

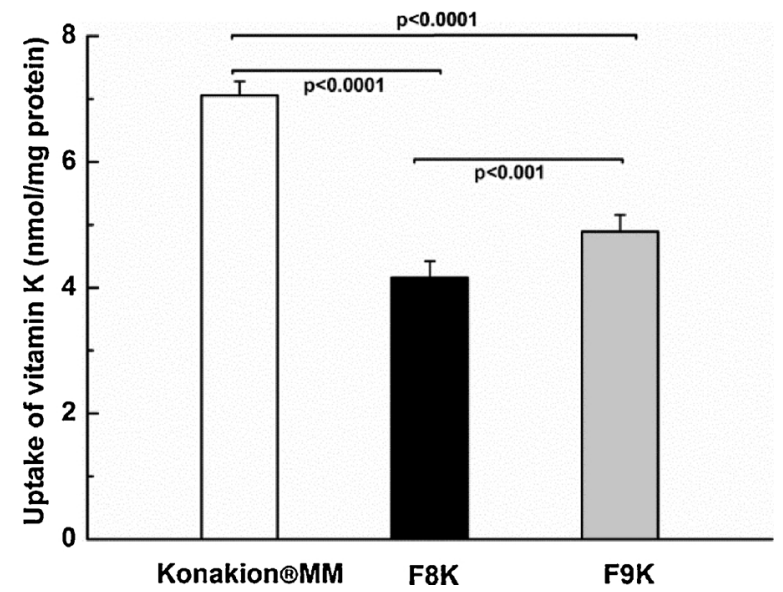

Fig. 4. Uptake of vitamin $\mathrm{K}$ upon incubation with Caco-2 cells for $2 \mathrm{~h}$ at $37^{\circ} \mathrm{C}$ with mixed micelles of Konakion ${ }^{\circledR}$ MM, F8K and F9K at a concentration of $0.24 \mathrm{mM}$ vitamin $\mathrm{K}$, one representative experiment in triplicate for each sample, results represent mean $\pm \mathrm{SD}, \mathrm{p}<0.0001$ or 0.001 is based on two-tailed unpaired $t$-test.

using a filter paper and the grid was dried for $5 \mathrm{~min}$ at room temperature before TEM analysis.

\subsection{Stability of vitamin $\mathrm{K}$ loaded mixed micelles at low $\mathrm{pH}$}

The $\mathrm{pH}$ of vitamin $\mathrm{K}$ loaded formulations $\mathrm{F} 8$ and $\mathrm{F} 9$ in water $(1 \mathrm{ml})$ was lowered to $\mathrm{pH} 1.5$ with $1 \mathrm{M} \mathrm{HCl}$ and the dispersions were subsequently incubated for $1 \mathrm{~h}$ at $37^{\circ} \mathrm{C}$. The size of the micelles was determined by DLS measurements at different time points $(0,10,20,40$ and $60 \mathrm{~min}$ ).

\subsection{Determination of vitamin $K$ and fluorescent probe concentrations in the formulations}

The concentration of vitamin $\mathrm{K}$ in different micellar dispersions was determined by RP-HPLC after dilution of the dispersions with ethanol using the same method as described in our previous study [5]. Briefly, a SunFire $\mathrm{C}_{18}$ column was used and absorption at $254 \mathrm{~nm}$ was used for detection. The mobile phase was ethanol/water $(95 / 5, \mathrm{v} / \mathrm{v})$. The column temperature was $30^{\circ} \mathrm{C}$ and the injection volume was $20 \mu \mathrm{A}$ calibration curve was obtained using vitamin $\mathrm{K}$ dissolved in ethanol with concentrations ranging from 10 to $100 \mu \mathrm{g} / \mathrm{ml}$.

For determination of the concentration of the fluorescent probe, mixed micelles $(100 \mu \mathrm{l})$ were dissolved by addition of ethanol $(900 \mu \mathrm{l})$ and the concentration of rhodamine-conjugated DSPE was determined using fluorescence measurements (FLUOstar Optima, BMG Labtech; for rhodamine conjugated DSPE: $\left.\lambda_{\mathrm{ex}}=560 \mathrm{~nm}, \quad \lambda_{\mathrm{em}}=590 \mathrm{~nm}\right)$. Calibration curves were obtained using rhodamine conjugated DSPE in ethanol (linear between 1 and $5 \mu \mathrm{g} / \mathrm{ml}$ ).

\subsection{Cytocompatibility of the mixed micellar formulations}

The viability of Caco-2 cells incubated with vitamin $\mathrm{K}$ loaded formulations F8K and F9K was evaluated by the MTS assay. In short, Caco2 cells were seeded in 96-well plates at a density of $1 \times 10^{5}$ cells per well and incubated in Dulbecco's modified Eagle's medium (DMEM) supplemented with $10 \%$ fetal bovine serum (FBS) at $37^{\circ} \mathrm{C}$ with $5 \% \mathrm{CO}_{2}$ for $24 \mathrm{~h}$ to allow attachment of the cells to the plates. Next, the medium was removed and $100 \mu$ mixed micelles diluted with blank DMEM ( $\mathrm{pH}$ 7.4) at different concentrations of total surfactants from 0.03 to $1.50 \mathrm{mg} / \mathrm{ml}$ were added to the wells. After $36 \mathrm{~h}$ of incubation at $37^{\circ} \mathrm{C}$, the medium was removed and $20 \mu$ l Celltiter $96^{\circledR}$ One Solution was introduced into each well. The plates were subsequently incubated for $2 \mathrm{~h}$ at $37^{\circ} \mathrm{C}$, after which the absorbance at $490 \mathrm{~nm}$ with a reference wavelength of $655 \mathrm{~nm}$ was measured by ELISA microplate reader (Biorad Novapath).

\subsection{Cellular uptake of vitamin $K$}

Caco- 2 cells $\left(1 \times 10^{5}\right.$ cells per well $)$ were seeded in a 24 well plate and grown in DMEM supplemented with $10 \%$ fetal bovine serum (FBS) at $37^{\circ} \mathrm{C}$ with $5 \% \mathrm{CO}_{2}$ for 3 weeks to form a confluent monolayer. Subsequently, the cells were incubated with F8K, F9K and Konakion ${ }^{\circledast}$ MM dispersed in blank DMEM at concentrations of $0.24 \mathrm{mM}$ vitamin $\mathrm{K}$ for a period of $2 \mathrm{~h}$ at $37^{\circ} \mathrm{C}$. Cells were 3 times washed with PBS and subsequently exposed to RIPA lysis buffer ( $150 \mathrm{mM} \mathrm{NaCl}, 1.0 \%$ Triton $\mathrm{X}-100,1 \%$ sodium deoxycholate, $0.1 \%$ SDS, $50 \mathrm{mM}$ Tris-HCl, $2 \mathrm{mM}$ EDTA, pH 8.0) for $10 \mathrm{~min}$ at $37^{\circ} \mathrm{C}$ and the obtained cell lysates were analyzed with micro BCA protein assay kit (Thermo Fisher Scientific, Perbio Science Nederland B.V) and HPLC to determine the protein and vitamin $\mathrm{K}$ concentrations, respectively. Triton X-100 can be used to lyse cells at a concentration between $0.1 \%$ and $1.0 \%$ [36]. Most frequently used is $1 \%$ [37-40], which is higher than its critical micelle concentration values (CMC, reported to be $0.01 \%-0.02 \%$ ) [41] to ensure the formation of micelles [42]. This concentration was therefore also used in our study. The HPLC method described by Marinova et al. was used with minor modification [43]. The mobile phase was methanol: ACN: HAc: water $(880 \mathrm{ml}: 120 \mathrm{ml}: 10 \mathrm{ml}: 5 \mathrm{ml}$, in which $1.2 \mathrm{~g} \mathrm{ZnAc}$ was dissolved). The eluent was flushed with nitrogen gas for $5 \mathrm{~min}$ before use. A SunFire $\mathrm{C}_{18}$ column was used for separation, and a reduction column $(5.5 \times 1.5 \mathrm{~cm}$, filled with zinc powder $60-70 \mu \mathrm{m})$ was attached to subsequently convert vitamin $\mathrm{K}$ into its reduced form to allow fluorescence detection. The flow rate was $1.2 \mathrm{ml} / \mathrm{min}$, the column temperature was $30^{\circ} \mathrm{C}$, and the excitation and emission wavelengths were 246 and $430 \mathrm{~nm}$, respectively. The injection volume was $100 \mu \mathrm{l}$ calibration curve was obtained using vitamin $\mathrm{K}$ in ethanol (linear between 10 and $500 \mathrm{ng} / \mathrm{ml}$ ).

For protein quantification, a micro BCA working reagent was prepared by mixing reagents MA, MB and MC (25:24:1, v/v/v) of the Micro BCA Assay Kit. Cell lysates $(150 \mu \mathrm{l})$ from each well were transferred into the wells of a microplate well. Then, $150 \mu \mathrm{l}$ of working reagent was added to the wells and mixed using a plate shaker for $30 \mathrm{~s}$. Next, the plate was covered using sealing tape and subsequently incubated at $37^{\circ} \mathrm{C}$ for $2 \mathrm{~h}$. Subsequently, the absorbance at $562 \mathrm{~nm}$ was measured on a plate reader. A calibration curve was obtained using BSA (bovine serum albumin) solutions with concentrations ranging from 1 to $200 \mu \mathrm{g} / \mathrm{ml}$. 

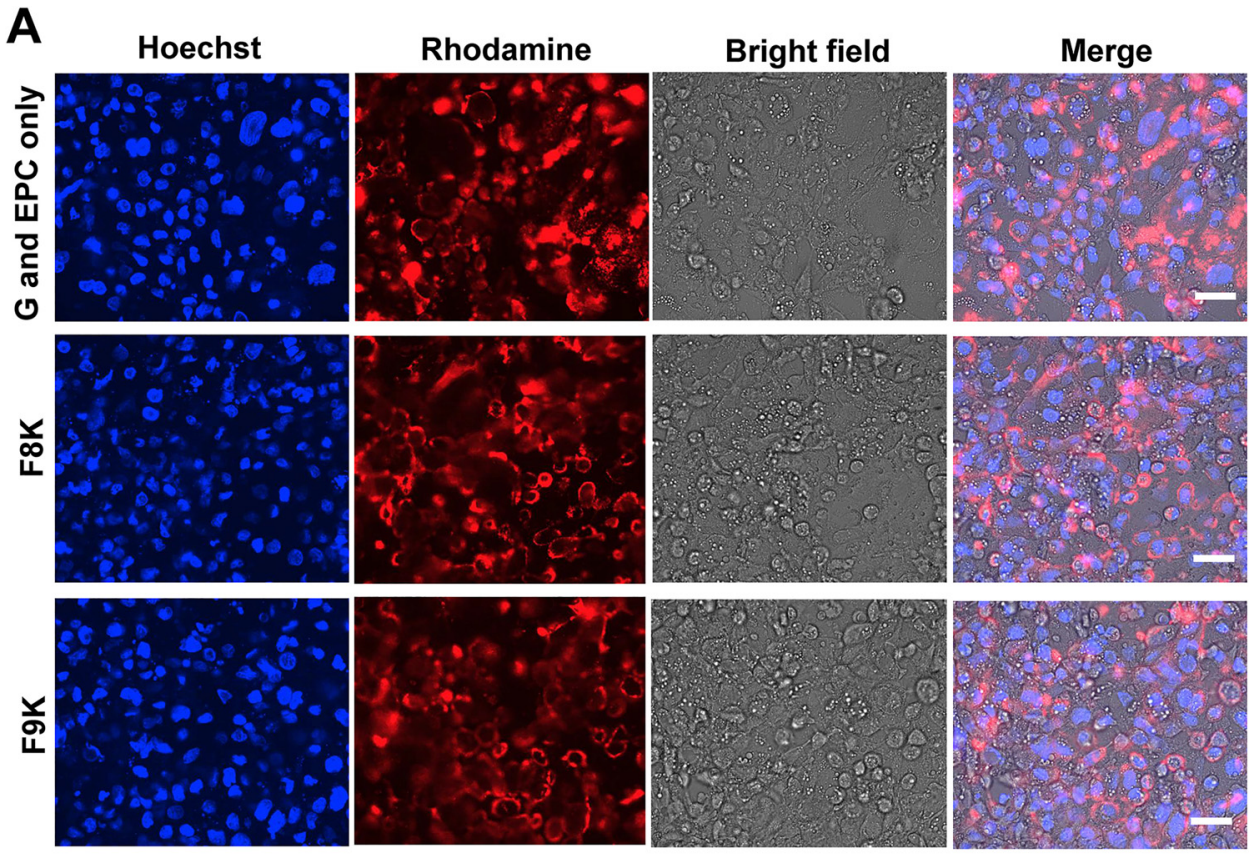

Fig. 5. (A) Confocal laser scanning microscopy pictures of Caco- 2 cell monolayers incubated for $2 \mathrm{~h}$ with rhodamine labeled vitamin $\mathrm{K}$ loaded mixed micelles of $\mathrm{G}$ and EPC only, F8K and $\mathrm{F9K}$, all at $37^{\circ} \mathrm{C}$ with concentration of $0.24 \mathrm{mM}$ vitamin $\mathrm{K}$. The fluorescence of Hoechst (blue), rhodamine (red), and brightfield image are merged in the right column (scale bar $=50 \mu \mathrm{m}$ ). (B) Normalized fluorescence intensity of rhodamine signal from three different wells for each sample shown in rhodamine channel from confocal laser scanning microscopy pictures, bars indicate average \pm SEM, $* * * * \mathrm{p}<0.0001$ and $* *$ $\mathrm{p}<0.001$ by Kurskal-Wallis test with Dunn's multiple comparisons (right). (For interpretation of the references to colour in this figure legend, the reader is referred to the web version of this article).

B

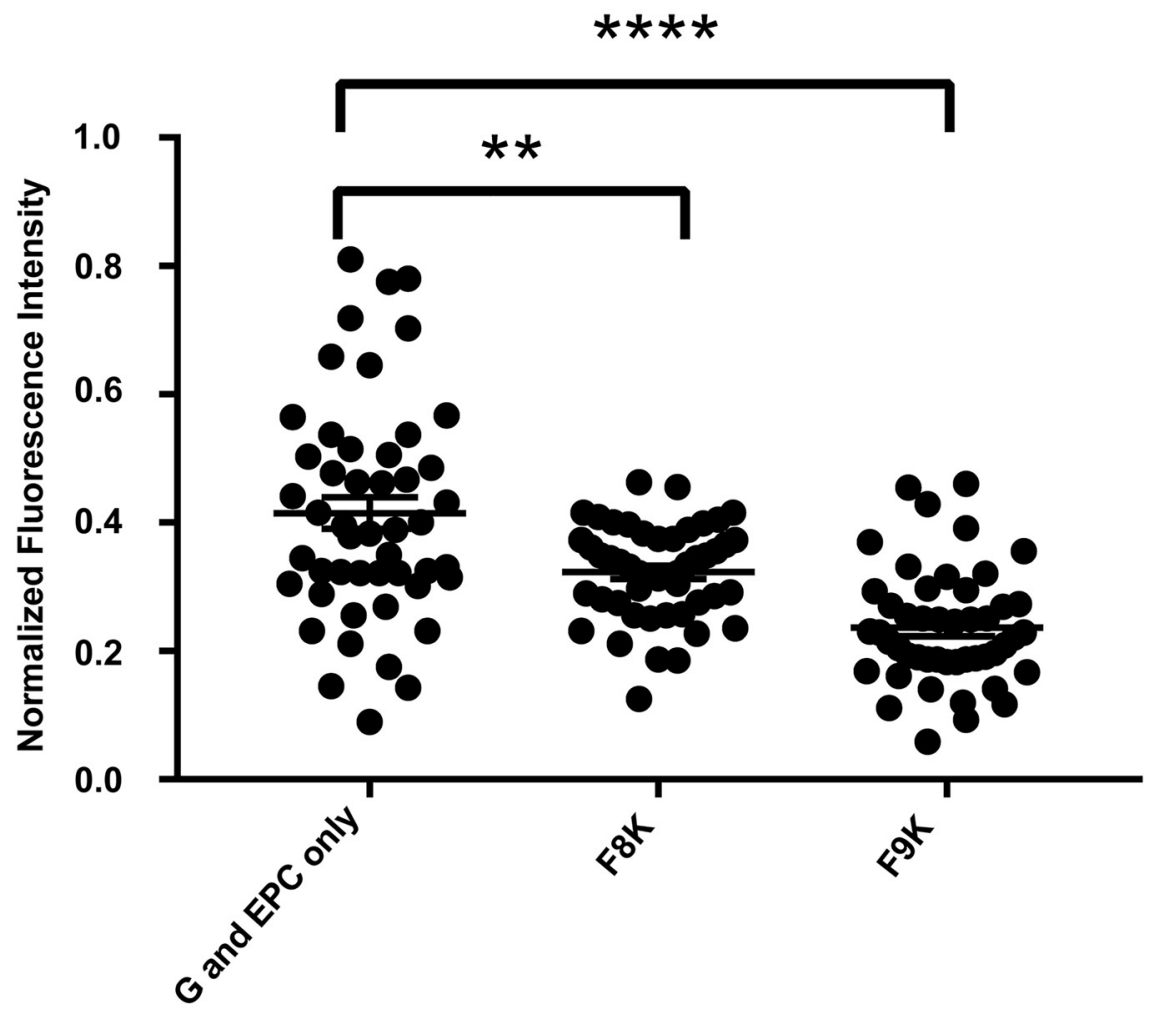

2.9. Cellular uptake of vitamin $K$ loaded rhodamine labeled mixed micelles studied by confocal microscopic analysis

Caco- 2 cells $\left(1 \times 10^{5}\right.$ cells per well) were seeded in a 96 well plate and grown in DMEM supplemented with $10 \%$ fetal bovine serum (FBS) at $37{ }^{\circ} \mathrm{C}$ with $5 \% \mathrm{CO}_{2}$ for 3 weeks to form a confluent monolayer. Next, rhodamine-DSPE labeled vitamin K loaded mixed micelles $(100 \mu \mathrm{l}, 5 \mu \mathrm{M}$ rhodamine-DSPE) were incubated with the cells for $2 \mathrm{~h}$. Subsequently, mixed micelles were removed and the cells were washed with PBS three times. The nuclei of live Caco-2 cells were stained with Hoechst dye 33342 ( $5 \mu \mathrm{M}$ in blank DMEM) for $20 \mathrm{~min}$ and the monolayers of Caco-2 cells were washed with PBS 3 times and exposed to $150 \mu$ l blank DMEM. Next, images were acquired using a high content imaging system (Cell Voyager CV-7000, Yokogawa) with excitation at $405 \mathrm{~nm}$ (nuclei staining) and $561 \mathrm{~nm}$ (rhodamine staining) at $60 \times$ objective. 


\subsection{Statistical analysis}

Statistical analysis was performed using Prism 7.0 software (GraphPad Software Inc.). Unpaired two-tailed student $t$-test ( $\mathrm{p}<0.0001$ or 0.001 ) or Kurskal-Wallis test with Dunn's multiple comparisons test $(* * * * \mathrm{p}<0.0001$ and $* * \mathrm{p}<0.001)$ were used as indicated in the figure legends.

\section{Results and discussion}

\subsection{Formulation optimization}

The aggregation number of bile salts is usually increased when incorporated in mixed micelles, i.e. from $2-10$ in form of primary micelles to 10-100 in form of secondary micelles [44,45], which are similar to Konakion ${ }^{\circledast}$ MM that includes a combination of glycocholic acid and EPC. Likewise, Mandal et al. have found that the aggregation number for some small peptides (di-, tri and tetra) and hydantoin drugs can be increased by surfactants [46-52]. In the present work, glycocholic acid was (partly) replaced by saponins to prevent coalescence of the commercial formulation (i.e. Konakion ${ }^{\circledast} \mathrm{MM}$ ) at gastric $\mathrm{pH}$ [4]. The preparation of mixed micelles was based on the method used in our previous publication with minor modification [5]. EPC with or without glycocholic acid was dissolved in chloroform/methanol to form a film after evaporation of the solvent, which was subsequently hydrated by a dispersion of saponins. Saponins are insoluble in chloroform/methanol and therefore they could not be mixed with EPC for formation of the thin film. Without glycocholic acid, micelles with a size above $90 \mathrm{~nm}$ were obtained, which were not stable and aggregated upon incubation for $16 \mathrm{~h}$ at $20^{\circ} \mathrm{C}$ (Supplementary material Fig. S1). The instability of such formulations can be attributed to the existence of out-of-equilibrium and meta-stable structures [53]. Bile salts often help in transformation of such meta-stable formulations into stable micelles [54], and therefore glycocholic acid was selected to obtain small-sized stable micelles. A quality-by-design approach based on extreme vertices experimental design was applied to find the optimal composition giving stable mixed micelles with sizes below $50 \mathrm{~nm}$ at $\mathrm{pH} 7.3$ and $\mathrm{pH} 1.5$ and the corresponding ratio of $\operatorname{size}_{(\mathrm{pH} \mathrm{1.5})} / \mathrm{size}_{(\mathrm{pH} \mathrm{7.3)}}<2$.

A quadratic model fitted the response values and the model was significant with a p-value $<0.0001$ (Table 1 ), which has relative high predicted $\mathrm{R}_{\text {squared }}$ and adequate precision (signal to noise ratio). Adequate precision values are greater than 4 , implying the suitability of the model. Eqs. (1)-(3) represent the polynomal equations for analysis of size at $\mathrm{pH} 7.3$ after preparation and at $\mathrm{pH} 1.5$ after incubating for $1 \mathrm{~h}$, and the corresponding ratio of size $\left.{ }_{(\mathrm{pH}} 1.5\right) / \mathrm{size}_{(\mathrm{pH}}$ 7.3) of various formulations, respectively: Size $_{(\mathrm{pH} 1.5)}=325 \times A+187 \times B+619 \times C-988 \times A \times B-1927 \times A \times C$
$+828 \times B \times C$

Size $($ pH 7.3) $=201 \times A+264 \times B+69 \times C-593 \times A \times B-295 \times A \times C$ $-372 \times B \times C-348 \times A \times C \times(A-C)-324 \times B \times C \times(B-C)-819 \times A \times C \times(A-$ $C)^{2}-855 \times B \times C \times(B-C)^{2}$

Ratio [Size $(\mathrm{pH} 1.5) /$ Size $(\mathrm{pH} 7.3)]=-11 \times A-7 \times B-3 \times C+$ $34 \times A \times B+42 \times B \times C-113 \times B \times C \times(B-C)+94 \times A \times B \times(A-B)^{2}+$ $202 \times A \times C \times(A-C)^{2}+265 \times B \times C \times(B-C)^{2}$

where $A, B$ and $C$ are the weight fractions (w/w) of EPC, saponins and glycocholic acid, respectively. Supplementary material Fig. S2 illustrates that predicted values (also shown in Supplementary material Table S1) according to these equations and the actual measured values were quite close to each other, especially for responses of size at $\mathrm{pH} 7.3$ (Supplementary material Fig. S2 A) and ratio of $\left.\operatorname{size}_{(\mathrm{pH} 1.5)} / \operatorname{size}_{(\mathrm{pH}} 7.3\right)$ (Supplementary material Fig. S2B). For responses of size at pH 1.5 (Supplementary material Fig. S2C), the predicted values deviated from several measured ones, because micelles composed of F11, F18 and
F24-27 were not stable and aggregated upon incubation at $\mathrm{pH} 1.5$ (giving large variation in sizes by DLS shown in Supplementary material Table S1 in bold), which makes the prediction less reliable.

Fig. 2A shows that the size of micelles at $\mathrm{pH} 7.3$ decreased with increasing concentration of $\mathrm{G}$ at a constant concentration of $\mathrm{S}$ (as shown in dash line in Fig. 2A). Glycocholic acid is inserted into the outermost planar bilayer, and subsequently large lamellar structures are transformed into smaller micelles [5]. For example, size of micelles F11 and F26 are smaller due to relative higher composition of $\mathrm{G}$ compared to the sizes of F3 and F4 at pH 7.3 (Supplementary material Table S1). However, Fig. 2B shows that at gastric $\mathrm{pH}$ of 1.5, a significant increase in size was observed with an increase of the concentration of $\mathrm{G}$ and at a constant concentration of $S$ (as shown in dash line in Fig. 2B). This means that increasing concentration of $\mathrm{G}$ makes the micelles unstable at low $\mathrm{pH}$. Correspondingly, the ratio of $\operatorname{size}_{(\mathrm{pH} \mathrm{1.5)}} / \operatorname{size}_{(\mathrm{pH} \text { 7.3) }}$ increased from about 1-40 (Fig. 2C), which can be explained by the higher amount of glycocholic acid that results in higher risk of instability of micelles due to protonation of the carboxylate group of glycocholic acid and a subsequent reduction in electrostatic repulsion between the micelles. Fig. 2D shows the overlay plot, generated after selecting the limits of sizes at $\mathrm{pH} 7.3$ and 1.5 below $50 \mathrm{~nm}$, and the corresponding ratio of $\operatorname{size}_{(\mathrm{pH} 1.5)} / \mathrm{size}_{(\mathrm{pH} \text { 7.3) }}$ below 2 (yellow area in Fig. 2D). As representative for the optimal formulations for loading of vitamin $\mathrm{K}$, two formulations were selected according to Fig. 2D, with responses that stayed within the optimized area, i.e. F8 and F9 (as indicated by arrows).

\subsection{Physicochemical characterization of vitamin $K$ loaded micelles}

F8K and F9K are mixed micelle formulations of F8 and F9 loaded with vitamin $\mathrm{K}$. To get insight into the maximum vitamin $\mathrm{K}$ loading of the mixed micelles, an increasing amount of vitamin $\mathrm{K}$ was added to a fixed amount of total lipid. Large particles with size above $200 \mathrm{~nm}$ were obtained when the feeding percentage of vitamin $\mathrm{K}$ against total lipid was $13.2 \%(\mathrm{w} / \mathrm{w})$ and $26.3 \%(\mathrm{w} / \mathrm{w})$. Supplementary material Table S2 and Supplementary material Fig. S3 present the results of the size distribution and zeta potential of these optimized micelles when the feeding percentage of vitamin $\mathrm{K}$ against total lipid was $10.0 \%(\mathrm{w} / \mathrm{w})$. The average sizes of micelles were 43 and $46 \mathrm{~nm}$ (Supplementary material Fig. S3A), and their zeta potentials were -16 to $-21 \mathrm{mV}$ (Supplementary material Fig. S3B), respectively. The negative zeta potential of the mixed micelles is caused by the presence of deprotonated carboxylic groups of glycocholic acid at $\mathrm{pH}$ 7.3. Vitamin $\mathrm{K}$ loaded F9K had a slightly less negative zeta potential (Supplementary material Table S2) because of its relative higher saponins content that caused shielding of the surface charge by the sugar chain of saponins.

With the feeding percentage of vitamin $\mathrm{K}$ against total lipid at $10.0 \%(\mathrm{w} / \mathrm{w})$, the vitamin $\mathrm{K}$ recovery, defined as the percentage of recovered vitamin $\mathrm{K}$ divided by the added amount of vitamin $\mathrm{K}$, was 85-90\% for both micellar formulations F8K and F9K. The corresponding vitamin $\mathrm{K}$ loading of the mixed micelles, defined as the percentage mass of vitamin $\mathrm{K}$ divided by the total mass of the mixed micelles, was $6.3-7.1 \%$. When rhodamine conjugated DSPE was added to the formulation, its recovery was high as well (89-95\%). The vitamin $\mathrm{K}$ recovery and vitamin $\mathrm{K}$ loading were not measured when the feeding percentage of vitamin $\mathrm{K}$ against total lipid was $13.2 \%(\mathrm{w} / \mathrm{w})$ and $26.3 \%$ (w/w) due to instability of the formulations.

The morphology of the particles was investigated by TEM analysis. As formulation of F8K has similar components and size compared to F9K, F8K was selected as a representative formulation for TEM measurements. Fig. S3C shows that small spherical micelles with size below $50 \mathrm{~nm}$ were observed, which confirmed the size as determined by DLS in Supplementary material Table S2 and Supplementary material Fig. S3A. 


\subsection{Stability of mixed micelles at gastric low $\mathrm{pH}$}

To investigate whether the introduction of saponins can improve the colloidal stability of glycocholic acid /EPC based vitamin K loaded mixed micelles at gastric $\mathrm{pH}$, the sizes of micelles were studied upon incubation in water at $\mathrm{pH} 1.5$ for $1 \mathrm{~h}$. Mandal and coworkers showed that the critical micelle concentration can be influenced by $\mathrm{pH}$ and hence micelle formation is dependent of $\mathrm{pH}$ [46-48]. However, the sizes of these vitamin $\mathrm{K}$ loaded $\mathrm{F} 8 \mathrm{~K}$ and F9K changed only from $43.1 \pm 1.1$ to $45.8 \pm 1.4 \mathrm{~nm}$ and from $45.9 \pm 2.3$ to $58.4 \pm 2.8 \mathrm{~nm}$, respectively (Supplementary material Fig. S4). The dispersions remained transparent and no coalescence of the formulation was observed, as opposed to Konakion ${ }^{\circ} \mathrm{MM}$ (which size at $\mathrm{pH} 7.3$ is around $7.1 \mathrm{~nm}$, and large aggregates were formed at $\mathrm{pH} 1.5$ (Supplementary material Fig. S5) [4,5]. In the case of saponins based micelles, the sugar moieties of saponins which are at the surface of the micelles (due to their hydrophilic character) likely avoid particle aggregation/coalescence caused by pronation of glycocholic acid at gastric low $\mathrm{pH}$. Therefore, saponins can indeed improve the colloidal stability of glycocholic acid/EPC based formulation at gastric $\mathrm{pH}$ for vitamin $\mathrm{K}$ loaded micelles.

\subsection{Cytocompatibility of saponins containing mixed micelles with vitamin $K$ loading}

In order to investigate the cytotoxicity of the saponins containing vitamin $\mathrm{K}$ loaded mixed micelles, the viability of Caco-2 cells after incubation with F8K and F9K was determined using the MTS assay. As shown in Fig. 3, the cell viability after $36 \mathrm{~h}$ of incubation with F8K and F9K was $>85 \%$ with concentration of surfactants (S and G) between 0.03 and $0.15 \mathrm{mg} / \mathrm{ml}$. The cell viability decreased from $85 \%$ to $32 \%$ when the concentration of total surfactants (S and G) increased from 0.15 to $1.50 \mathrm{mg} / \mathrm{ml}$. The toxic effect of glycocholic acid and saponins at higher levels correlates with previous finding [55,56]. Therefore, F8K and F9K showed good cytocompatibility at concentrations of surfactants (S and G) below $0.15 \mathrm{mg} / \mathrm{ml}$ and were further studied for their cellular uptake by Caco-2 cells.

\subsection{Uptake of vitamin K loaded rhodamine labeled mixed micelles by Caco- 2 cells}

As absorption enhancers, both saponins and glycocholic acid can disrupt the lipid arrangements in cell membranes and interact with the polar head groups of the lipid bilayers [24,57]. As a consequence, the lipid membrane becomes fluidized which promotes the diffusion of drugs and even intact micelles across the cell membrane [24,58]. To investigate the uptake of F8K and F9K by intestinal epithelium, Caco-2 cells were selected as a model for small intestinal epithelial cells [59-61]. The commercial formulation Konakion ${ }^{\circledR}$ MM was applied as a positive control. After $2 \mathrm{~h}$ incubation with Caco- 2 cells at $37^{\circ} \mathrm{C}$, the vitamin $\mathrm{K}$ uptake by the cells was $7.1 \pm 0.2,4.2 \pm 0.3$ and $4.9 \pm 0.3 \mathrm{nmol} / \mathrm{mg}$ protein for Konakion ${ }^{\circledR} \mathrm{MM}$, and F8K and F9K, respectively (Fig. 4). The uptake of vitamin $\mathrm{K}$ was higher for Konakion ${ }^{\circledR}$ MM compared to saponins containing micelles, which is probably because bile salts showed higher permeabilization of Caco- 2 cells than saponins [24] and Konakion ${ }^{\circledR}$ MM have a smaller size than saponins containing micelles (about 7 and $43 \mathrm{~nm}$, respectively). However, it is important to note that the uptake of vitamin $\mathrm{K}$ was not dramatically reduced when glycocholic acid was partly substituted by saponins.

Furthermore, the cellular uptake of the micelles was monitored by confocal microscopic analysis using mixed micelles that were fluorescently labeled with rhodamine-DSPE to visualize the internalization by and intracellular localization of micelles in Caco-2 cells. The nuclei of Caco- 2 cells were stained by Hoechst 33342 , which presented blue fluorescence to distinguish from the red fluorescence from the rhodamine-PE labeled micelles (Fig. 5A). The fluorescent signal of rhodamine in red indicates that micelles are taken up by the cells, however the fluorescent intensity of rhodamine from micelles of F8K and $\mathrm{F} 9 \mathrm{~K}$ (Fig. 5B) displayed relatively lower fluorescence intensity than that from micelles that lack saponins (similar to Konakion ${ }^{\circledR} \mathrm{MM}$ ), which is consistent with the uptake of vitamin $\mathrm{K}$ as shown in Fig. 4.

\section{Conclusions}

The commercial vitamin $\mathrm{K}$ formulation Konakion ${ }^{\circledR} \mathrm{MM}$ is unstable and large aggregates are formed at low $\mathrm{pH}$ because of protonation of the constituent bile acid, which accounts for the reduced bioavailability under cholestatic conditions. Therefore, improving the stability at low $\mathrm{pH}$ was the goal of the present work. In this study, vitamin $\mathrm{K}$ loaded mixed micelles composed of saponins, glycocholic acid and EPC were successfully prepared by a film hydration method combined with probe sonication. Saponins-containing formulations, optimized using an extreme vertices design approach, showed good cytocompatibility for Caco-2 cells. Cellular uptake of saponins-containing mixed micelles was slightly reduced as compared to Konakion ${ }^{\circledR} \mathrm{MM}$, however the superior stability at low $\mathrm{pH}$ makes it a promising oral formulations for vitamin $\mathrm{K}$ for the prophylaxis and treatment of vitamin $\mathrm{K}$ deficiency bleeding in neonates and infants suffering from cholestasis.

\section{Acknowledgements}

This work was supported by China Scholarship Council. Thank StatEase, Inc. for a free license of Design Expert version 10.

\section{Appendix A. Supplementary data}

Supplementary material related to this article can be found, in the online version, at doi:https://doi.org/10.1016/j.colsurfb.2018.06.049.

\section{References}

[1] C. Vermeer, Gamma-carboxyglutamate-containing proteins and the vitamin K-dependent carboxylase, Biochem. J. 266 (1990) 625-636.

[2] Limited Roche Products, Summary of Product Characteristics of Konakion MM Paediatric (assessed May 2015), www.medicines.org.uk/emc/print-document? documentId $=1699$.

[3] R. Von Kries, A. Hachmeister, U. Göbel, Oral mixed micellar vitamin K for prevention of late vitamin K deficiency bleeding, Arch. Dis. Child. Fetal Neonatal Ed. 88 (2003) F109-F112.

[4] P.M. van Hasselt, Vitamin K Prophylaxis Revisited: Focus on Risk Factors. Thesis, Utrecht University, Utrecht, 2009 Chapter 7.

[5] F. Sun, T.C. Jaspers, P.M. van Hasselt, W.E. Hennink, C.F. van Nostrum, A mixed micelle formulation for oral delivery of vitamin K, Pharm. Res. 33 (2016) 2168-2179.

[6] A. Gothwal, I. Khan, U. Gupta, Polymeric micelles: recent advancements in the delivery of anticancer drugs, Pharm. Res. 33 (2016) 18-39.

[7] J.H. Fagerberg, E. Karlsson, J. Ulander, G. Hanisch, C.A. Bergström, Computational prediction of drug solubility in fasted simulated and aspirated human intestinal fluid, Pharm. Res. 32 (2015) 578-589.

[8] J. Iqbal, M.M. Hussain, Intestinal lipid absorption, Am. J. Physiol. Endocrinol. Metab. 296 (2009) E1183-E1194.

[9] O. Hernell, J.E. Staggers, M.C. Carey, Physical-chemical behavior of dietary and biliary lipids during intestinal digestion and absorption. 2. Phase analysis and aggregation states of luminal lipids during duodenal fat digestion in healthy adult human beings, Biochemistry 29 (1990) 2041-2056.

[10] V. Leiro, P. Moreno, B. Sarmento, J. Durão, L. Gales, A. Pêgo, C. Barrias, Lígia Rodrigues, Manuel Mota (Eds.), Bioinspired Materials for Medical Applications, Elsevier, Amsterdam, 2017Chapter 1.

[11] C. Zhao, H. Deng, J. Xu, S. Li, L. Zhong, L. Shao, Y. Wu, X.-j. Liang, "Sheddable" PEG-lipid to balance the contradiction of PEGylation between long circulation and poor uptake, Nanoscale 8 (2016) 10832-10842.

[12] Y. Bao, Y. Jin, P. Chivukula, J. Zhang, Y. Liu, J. Liu, J.-P. Clamme, R.I. Mahato, D. Ng, W. Ying, Effect of PEGylation on biodistribution and gene silencing of siRNA/lipid nanoparticle complexes, Pharm. Res. 30 (2013) 342-351.

[13] S. Hama, S. Itakura, M. Nakai, K. Nakayama, S. Morimoto, S. Suzuki, K. Kogure, Overcoming the polyethylene glycol dilemma via pathological environment-sensitive change of the surface property of nanoparticles for cellular entry, J. Control. Release 206 (2015) 67-74.

[14] E. Moghimipour, S. Handali, Saponin: properties, methods of evaluation and applications, Annu. Res. Rev. Biol. 5 (2015) 207.

[15] Z. Liu, J. Wang, W. Gao, S. Man, H. Guo, J. Zhang, C. Liu, Formulation and in vitro 
absorption analysis of Rhizoma paridis steroidal saponins, Int. J. Pharm. 441 (2013) 680-686.

[16] H. Salminen, S. Aulbach, B.H. Leuenberger, C. Tedeschi, J. Weiss, Influence of surfactant composition on physical and oxidative stability of Quillaja saponin-stabilized lipid particles with encapsulated $\omega-3$ fish oil, Colloids Surf. B Biointerfaces 122 (2014) 46-55.

[17] S. Böttcher, S. Drusch, Saponins-self-assembly and behavior at aqueous interfaces, Adv. Colloid. Interface Sci. (2017) 105-113.

[18] S. Mitra, S.R. Dungan, Micellar properties of quillaja saponin. 2. Effect of solubilized cholesterol on solution properties, Colloids Surf. B Biointerfaces 17 (2000) 117-133.

[19] K. Wojciechowski, Surface activity of saponin from Quillaja bark at the air/water and oil/water interfaces, Colloids Surf. B Biointerfaces 108 (2013) 95-102.

[20] Product Information of Saponins from Sigma-Aldrich, (2018) Available from: https://www.sigmaaldrich.com/catalog/product/sigma/84510?lang = en\& region $=$ NL (assessed Feb 2018).

[21] K. Urum, T. Pekdemir, Evaluation of biosurfactants for crude oil contaminated soil washing, Chemosphere 57 (2004) 1139-1150.

[22] C. Bachran, M. Sutherland, I. Heisler, P. Hebestreit, M.F. Melzig, H. Fuchs, The saponin-mediated enhanced uptake of targeted saporin-based drugs is strongly dependent on the saponin structure, Exp. Biol. Med. 231 (2006) 412-420.

[23] M. Thakur, M.F. Melzig, H. Fuchs, A. Weng, Chemistry and pharmacology of saponins: special focus on cytotoxic properties, Botanics 1 (2011) 19-29.

[24] E. Moghimipour, S.A.S. Tabassi, M. Ramezani, S. Handali, R. Löbenberg, Brush border membrane vesicle and Caco-2 cell line: Two experimental models for evaluation of absorption enhancing effects of saponins, bile salts, and some synthetic surfactants, J. Adv. Pharm. Technol. Res. 7 (2016) 75.

[25] P.S. Lee, J.-Y. Han, T.W. Song, J.H. Sung, O.-S. Kwon, S. Song, Y.B. Chung, Physicochemical characteristics and bioavailability of a novel intestinal metabolite of ginseng saponin (IH901) complexed with $\beta$-cyclodextrin, Int. J. Pharm. 316 (2006) 29-36.

[26] E. Abramov, F. Cassiola, O. Schwob, A. Karsh-Bluman, M. Shapero, J. Ellis D. Luyindula, I. Adini, R.J. D'Amato, O. Benny, Cellular mechanism of oral absorption of solidified polymer micelles, Nanomed. Nanotech. Biol. Med. 11 (2015) 1993-2002.

[27] K. Réti-Nagy, M. Malanga, É. Fenyvesi, L. Szente, G. Vámosi, J. Váradi, I. Bácskay, P. Fehér, Z. Ujhelyi, E. Róka, M. Vecsernyés, G. Balogh, G. Vasvári, F. Fenyvesi, Endocytosis of fluorescent cyclodextrins by intestinal Caco-2 cells and its role in paclitaxel drug delivery, Int, J. Pharm. 496 (2015) 509-517.

[28] E.S. Rothman, M.E. Wall, C.R. Eddy, Steroidal sapogenins. III. structure of steroidal saponins ${ }^{2}$, J. Am. Chem. Soc. 74 (1952) 4013-4016.

[29] B.L. Stegelmeier, R. Field, K.E. Panter, J.O. Hall, K.D. Welch, J.A. Pfister, D.R. Gardner, S.T. Lee, S. Colegate, T.Z. Davis, Selected Poisonous Plants Affecting Animal and Human Health vol. II, Academic press, Cambridge, 2013 Chapter 40.

[30] A.K. Jain, K. Thanki, S. Jain, Solidified self-nanoemulsifying formulation for oral delivery of combinatorial therapeutic regimen: part I. Formulation development, statistical optimization, and in vitro characterization, Pharm. Res. 31 (2014) 923-945.

[31] G.C. Yang, S.I. Ao, X. Huang, O. Castillo, Transactions on Engineering Technologies: International MultiConference of Engineers and Computer Scientists, Springer, New York, 2014 p. 275.

[32] K. Thanki, X. Zeng, S. Justesen, S. Tejlmann, E. Falkenberg, E. Van Driessche, H.M. Nielsen, H. Franzyk, C. Foged, Engineering of small interfering RNA-loaded lipidoid-poly (DL-lactic-co-glycolic acid) hybrid nanoparticles for highly efficient and safe gene silencing: a quality by design-based approach, Eur. J. Pharm. Biopharm. 120 (2017) 22-33.

[33] L. Zhao, J. Du, Y. Duan, Yn. Zang, H. Zhang, C. Yang, F. Cao, G. Zhai, Curcumin loaded mixed micelles composed of pluronic P123 and F68: preparation, optimization and in vitro characterization, Colloids Surf. B Biointerfaces 97 (2012) 101-108.

[34] Y. Duan, B. Zhang, L. Chu, H.H.Y. Tong, W. Liu, G. Zhai, Evaluation in vitro and in vivo of curcumin-loaded mPEG-PLA/TPGS mixed micelles for oral administration, Colloids Surf. B Biointerfaces 141 (2016) 345-354.

[35] R. Ganguly, A. Kunwar, B. Dutta, S. Kumar, K.C. Barick, A. Ballal, V.K. Aswal, P.A. Hassan, Heat-induced solubilization of curcumin in kinetically stable pluronic P123 micelles and vesicles: an exploit of slow dynamics of the micellar restructuring processes in the aqueous pluronic system, Colloids Surf. B Biointerfaces 152 (2017) $176-182$.

[36] H. Ji, Lysis of cultured cells for immunoprecipitation, Cold Spring Harb. Protoc. (2010) 2010 pdb.prot5466.

[37] M.H. Klose, M. Hejl, P. Heffeter, M.A. Jakupec, S.M. Meier-Menches, W. Berger, B.K. Keppler, Post-digestion stabilization of osmium enables quantification by ICP-
MS in cell culture and tissue, Analyst 142 (2017) 2327-2332.

[38] M. Caralt, J.S. Uzarski, S. Jacob, K.P. Obergfell, N. Berg, B.M. Bijonowski, K.M. Kiefer, H.H. Ward, A. Wandinger-Ness, W.M. Miller, Optimization and critical evaluation of decellularization strategies to develop renal extracellular matrix scaffolds as biological templates for organ engineering and transplantation, Am. J. Transpl. 15 (2015) 64-75.

[39] X. Liu, Z. Zhang, J. Ruan, Y. Pan, V.G. Magupalli, H. Wu, J. Lieberman, Inflammasome-activated gasdermin D causes pyroptosis by forming membrane pores, Nature 535 (2016) 153.

[40] D. Chen, T. Kluz, L. Fang, X. Zhang, H. Sun, C. Jin, M. Costa, Hexavalent chromium (Cr (VI) down-regulates acetylation of histone $\mathrm{H} 4$ at lysine 16 through induction of stressor protein Nupr1, PloS One 11 (2016) e0157317.

[41] P. Holloway, A simple procedure for removal of triton X-100 from protein samples, Anal. Biochem. 53 (1973) 304-308.

[42] N.N. Fathima, A. Rajaram, B. Sreedhar, A.B. Mandal, The formation of copper oxide nanorods in the presence of various surfactant micelles, Indian J. Sci. Technol. 1 (2008) 1-6.

[43] M. Marinova, D. Lütjohann, P. Westhofen, M. Watzka, O. Breuer, J. Oldenburg, A validated HPLC method for the determination of vitamin $\mathrm{K}$ in human serum-first application in a pharmacological study, Open Clin. Chem. J. 4 (2011) 17-27.

[44] S. Mukhopadhyay, U. Maitra, Chemistry and biology of bile acids, Curr. Sci. 87 (2004) 1666-1683.

[45] E. Moghimipour, A. Ameri, S. Handali, Absorption-enhancing effects of bile salts, Molecules 20 (2015) 14451-14473.

[46] A.B. Mandal, R. Jayakumar, Aggregation, hydrogen bonding and thermodynamic studies on tetrapeptide micelles, Chem. Soc. Faraday Trans. 90 (1994) 161-165.

[47] A. BaranáMandal, A new micelle-forming peptide, J. Chem. Soc. Chem. Commun. (1993) 237-238.

[48] A. Mandal, A. Dhathathreyan, R. Jayakumar, T. Ramasami, Characterisation of -Lys (Z)-Tyr-NHNH2 dipeptide. Part 1. physico-chemical studies on the micelle formation of a dipeptide in the absence and presence of ionic surfactants, Chem. Soc. Faraday Trans. 89 (1993) 3075-3079.

[49] R. Jayakumar, R. Jeevan, A. Mandal, P. Manoharan, Aggregation, hydrogen bonding and thermodynamic studies on Boc-Val-Val-Ile-OMe tripeptide micelles in chloroform, Chem. Soc. Faraday Trans. 90 (1994) 2725-2730.

[50] R. Jayakumar, A. Mandal, P. Manoharan, Micelle formation of Boc-Val-Val-Ile-OMe tripeptide in chloroform and its conformational analysis, J. Chem. Soc. Chem. Commun. (1993) 853-855.

[51] A. Mandal, R.S.G. Krishnan, S. Thennarasu, S. Panigrahi, A.B. Mandal, Two-dimensional surface properties of an antimicrobial hydantoin at the air-water interface: an experimental and theoretical study, Colloids Surf. B Biointerfaces 79 (2010) $136-141$.

[52] L.K. Tiwary, A. Mandal, M.S. Alam, S. Thennarasu, A.B. Mandal, Thermodynamics studies on tyrosine-hydantoin drug-cetyltrimethylammonium bromide mixed micellar system, Colloids Surf. B Biointerfaces 82 (2011) 126-133.

[53] V. Guida, Thermodynamics and kinetics of vesicles formation processes, Adv. Colloid Interface Sci. 161 (2010) 77-88.

[54] L. Jiang, K. Wang, M. Deng, Y. Wang, J. Huang, Bile salt-induced vesicle-to-micelle transition in catanionic surfactant systems: steric and electrostatic interactions, Langmuir 24 (2008) 4600-4606.

[55] Yn. Tan, J. Qi, Y. Lu, F. Hu, Z. Yin, W. Wu, Lecithin in mixed micelles attenuates the cytotoxicity of bile salts in Caco-2 cells, Toxicol. In Vitro 27 (2013) 714-720.

[56] M. Arabski, A. Węgierek-Ciuk, G. Czerwonka, A. Lankoff, W. Kaca, Effects of saponins against clinical E. coli strains and eukaryotic cell line, J. Biomed. Biotechnol. 2012 (2012) 1.

[57] B. Korchowiec, M. Gorczyca, K. Wojszko, M. Janikowska, M. Henry, E. Rogalska, Impact of two different saponins on the organization of model lipid membranes, Biochim. Biophys. Acta Biomembr. 1848 (2015) 1963-1973.

[58] Y.-1. Lo, Relationships between the hydrophilic-lipophilic balance values of pharmaceutical excipients and their multidrug resistance modulating effect in Caco-2 cells and rat intestines, J. Control. Release 90 (2003) 37-48.

[59] P. Artursson, Epithelial transport of drugs in cell culture. I: a model for studying the passive diffusion of drugs over intestinal absorbtive (Caco-2) cells, J. Pharm. Sci. 79 (1990) 476-482.

[60] A. Parr, I.J. Hidalgo, C. Bode, W. Brown, M. Yazdanian, M.A. Gonzalez, K. Sagawa, K. Miller, W. Jiang, E.S. Stippler, The effect of excipients on the permeability of BCS class III compounds and implications for biowaivers, Pharm. Res. 33 (2016) 167-176.

[61] A. Beloqui, P.B. Memvanga, R. Coco, S. Reimondez-Troitiño, M. Alhouayek, G.G. Muccioli, M.J. Alonso, N. Csaba, M. de la Fuente, V. Préat, A comparative study of curcumin-loaded lipid-based nanocarriers in the treatment of inflammatory bowel disease, Colloids Surf. B Biointerfaces. 143 (2016) 327-335. 